\title{
Gianni Vattimo: política y democracia. Más conflicto que diálogo
}

\section{Gianni Vattimo: politics and democracy. More conflict than dialogue}

Cómo citar este artículo en APA: Rivera, V. S. (2021). Gianni Vattimo: política y democracia. Más conflicto que diálogo. Analecta Política, 11(21), 201-224.

doi: http://dx.doi. org/10.18566/apolit. v11n21.a02

Fecha de recepción: 19.06.2020

Fecha de aceptación: 23.09.2021 Orcid: hitps://orcid.org/0000-0002-6388-3096 


\section{Resumen}

Este artículo intenta esclarecer el concepto de democracia dentro de la hermenéutica nihilista de Gianni Vattimo. El objetivo principal es establecer las pautas que dan sentido a la retórica del autor en torno de temas públicos, que este encuentra ligado a un marco conceptual que la historiografía conoce como la posición "heideggeriana de izquierdas". Este heideggerianismo se pretende de izquierdas en tanto agenda anarquista o comunista contra las instituciones de la democracia liberal como parte de un diagnóstico pesimista sobre el régimen hegemónico del Occidente, que considera "metafísico" y "falta de emergencia", esto es, supuestamente impermeable a los cambios y reivindicaciones sociales. El turinés, sin embargo, pretende ser partidario de la democracia en un sentido distinto, en la fórmula "del diálogo al conflicto"; en este contexto, intentaremos mostrar el uso efectivo de "democracia" como concepto político y social en las obras de Vattimo, observar sus posibles incoherencias y ver la manera de encontrarles consistencia discursiva. Para eso, se va a mostrar que el turinés se halla dentro de una versión pluralista de la democracia por medio de un análisis comparativo con la versión radical de la democracia ofrecida por Chantall Mouffe en 2004. Con este procedimiento, se intenta dar indicios para reinterpretar la posición heideggeriana de izquierda como una forma alternativa de régimen político liberal en la clave pluralista o de democracia radical hermenéutica. Como un balance, esta propuesta de incorporar la retórica nihilista en una teoría democrática tendría la ventaja de dar cabida conceptual a los conflictos sociales como parte de las dinámicas de reconocimiento de la diversidad dentro de la democracia, pasando desde una postura metafísica y cerrada a otra abierta a la escucha de la diferencia y el cambio social.

Palabras clave: anarquismo, comunismo, conflicto social, democracia, exclusión social, filosofía política, pluralismo, resistencia al cambio

\section{Abstract}

This article seeks to clarify the concept of democracy within Gianni Vattimo's nihilistic hermeneutics. The main objective is to establish the guidelines that give meaning to the author's rhetoric around public issues, which is linked to a conceptual framework known by historiography as the "left Heideggerian" position. This Heideggerianism is intended to be left-wing as an anarchist or communist agenda against the institutions of liberal democracy as part of a pessimistic diagnosis of the hegemonic regime of the West, which it considers "metaphysical" and "lack of emergency", that is, supposedly impervious to changes and social demands. The Turinese, however, pretends to be a supporter of democracy in a different sense, in the formula "from dialogue to conflict". In this context, we will try to show the effective use of "democracy" as a political and 
social concept in the works of Vattimo, as well as to observe its possible inconsistencies and to find discursive consistency in them. To do this, it will be shown that the Turinese is within a pluralist version of democracy by means of a comparative analysis with the radical version of democracy offered by Chantall Mouffe in 2004. With this procedure, an attempt is made to give indications to reinterpret the left Heideggerian position as an alternative form of liberal political regime in the pluralist key or the hermeneutic radical democracy. As a balance, this proposal to incorporate nihilist rhetoric into a democratic theory would have the advantage of giving conceptual space to social conflicts as part of the dynamics of recognition of diversity within democracy, moving from a metaphysical and closed position to one open to listening to difference and social change.

Keywords: anarchism, communism, social conflict, democracy, social exclusion, political philosophy, pluralism, resistance to change.

\section{Introducción: la hermenéutica de la autoridad}

Este artículo está pensado para orientar al lector de la obra político-social de Gianni Vattimo, uno de los filósofos contemporáneos más polifacéticos y fluidos del espectro de la hermenéutica y las corrientes posmodernas en filosofía, fundador de lo que se conoce como "hermenéutica nihilista", resultado de una peculiar interpretación de la ontología de Heidegger desde una lectura nihilista de Nietzsche (Giorgio, 2009a; Leiro, 2007). De acuerdo con esta postura, la hermenéutica filosófica es instalada como el discurso de una época, el discurso más propio para las sociedades democráticas capitalistas avanzadas dentro y como expresión de una orientación política del conjunto de la historia del Occidente; la hermenéutica sería el lenguaje más propio de esa época, su "nueva koiné” (Vattimo, 1991, pp. 55 y ss.). Vattimo sostuvo esto como programa de la hermenéutica en general en el proyecto colectivo de 1983 El pensamiento débil (Vattimo y Rovatti, 1988), ratificado después en 1989 en Ética de la interpretación; este último volumen era una compilación de conferencias sobre cuestiones éticas y políticas que le daría cabida a Vattimo como uno de los pensadores más llamativos de su tiempo, en particular en Italia y los países de habla española. En los textos más recientes, estas aspiraciones de la hermenéutica se integraron con una cierta retórica sobre la democracia, por lo que este artículo tiene como objetivo principal intentar examinar qué es la democracia en esta retórica de Vattimo. El turinés usa el término sin haberlo precisado nunca como parte del bagaje del lenguaje corriente. 
Una manera fácil de pensar bastante genérica, pero no inexacta, de tratar el tema sería declarar que como intelectual Vattimo suscribe programas "de izquierdas" y que, singularmente, escribe sus ensayos de prensa o sus conferencias para un público amplio "progresista". Las agendas que Vattimo suscribe son polémicas y a veces contradictorias, en especial en lo relativo con su concepción de la democracia misma. Abandonada a un público progresista "de izquierdas", estaría interesado en agendas de "emancipación" y no estaría, en cambio, muy al tanto de si estas son coherentes o no con su soporte filosófico. La idea de que esta versión del vínculo entre democracia y pensamiento "de izquierdas" es, por poco decir, problemática, ha sido a veces considerada una ventaja de la retórica de Vattimo, como el bienvenido desarrollo de "la vena anárquica de la hermenéutica" y como fuente de un deseable "anarcocomunismo" (Grijalba, 2018, Milla, 2013; pp. 78, 85; Vattimo y Zabala, 2011, pp. 75 y ss.).

Como hemos visto, es frecuente tratar de las ideas políticas de Vattimo como si fuera un hecho evidente que estas son coherentes y se infieren de los argumentos filosóficos que usa, y que no hay nada problemático entre las preferencias de Vattimo (el populismo latinoamericano, por ejemplo) y su diagnóstico de la democracia y, ciertamente, la democracia misma como un conjunto de prácticas y valores en el que la reflexión tiene sentido (Leiro, 2007). A lo anterior, como actitud de lectura, lo llamaremos "la hermenéutica de la autoridad": el maestro de Turín lo afirma, entonces, asumimos que es coherente.

No sobra declarar que la hermenéutica de la autoridad no es una forma satisfactoria de justificar las agendas prácticas con las que Vattimo asocia su "hermenéutica nihilista”, como se ha notado antes (Llorente, 2016; Rivera, 2015). Hay una incertidumbre frente al pensamiento de Vattimo en las sociedades democráticas que se desprende de esto y que podría alimentar sospechas de que el "anarcocomunismo" no es sino un puro irracionalismo (Grondin, 2008, pp. 166167). Su última justificación y fuente de validez sería su adhesión a la izquierda, su voluntad por las izquierdas. Esta solución ha sido alimentada hace no poco por el propio autor (Vattimo, 2018), que ha explayado las consecuencias políticas de su pensamiento en esta vena del "nihilismo" desde un punto de vista voluntarista. El propio turinés habría situado este enfoque voluntarista en la herencia del antimodernismo del "Heidegger de la Selva Negra" (Vattimo, 2010, p. 27), es decir, del Heidegger que abrazó la causa de Hitler.

Vattimo afirma que la vía de la Selva Negra es "un riesgo que debemos correr", algo que ya se hubo estipulado en realidad desde muy temprano, en una conferencia sobre hermenéutica de izquierda y democracia de 1990 (Zabala, 2004, p. 
27). Se trata de "un llamado del Ser" (Vattimo y Zabala, 2011, p. 94; Vattimo, 2018, cap. 6), un destino del que no sería posible apartarse y en el que la democracia jugaría el riesgo de su propia disolución (Miller, 2009; Vattimo, 2010, p. 29). Pero ¿por qué deberíamos correr ese riesgo? ¿Cuál es la relación entre este programa de anarquismo filosófico con la democracia más allá de las pretensiones entusiastas de la hermenéutica de la autoridad? Una posibilidad sería integrar las ideas sociales de Vattimo en una concepción de la democracia que disponga de herramientas que posiblemente Vattimo no tiene para incorporar los riesgos del nihilismo en la democracia y no siempre y necesariamente desde fuera de ella, para lo que apelaremos a la democracia radical, tal y como la defiende Chantall Mouffe en En torno de lo político (2004).

\section{Vattimo y la política: los giros del segundo Vattimo}

Si bien desde muy temprano Vattimo manifestó un interés político para su versión de la hermenéutica, cosa que puede anotarse desde su colección de ensayos tempranos, a partir de 1961 e impresa en 1974, El sujeto y la máscara (Leiro, 2007, pp. 201-202), la filosofía política no ocupó mayor lugar en la obra de Vattimo, sino hasta mucho después, hasta 2003, en que apareció Nibilismo y emancipación. Este último texto es una compilación que estuvo a cargo de Santiago Zabala, filósofo norteamericano que ha influenciado grandemente en Vattimo en este aspecto, armada esta compilación para dar un vuelco político a la hermenéutica nihilista. A partir de allí, el turinés pasa de la estética a la política, con la intención de generar un discurso en que la "nueva koiné" de la década de 1980 pasara a comprometerse con los temas sociales y aun la práctica política del siglo XXI; esta posición, como ya sabe el lector, no sería neutral, sino que estaría signada desde la izquierda, como en el programa de 1974, en una posición denominada "heideggeriana de izquierda" (Woodward, 2009, pp. 77-78). Desde el punto de vista biográfico, es evidente que esto pasa por el interés del propio autor por la política, a la que se dedica activamente en el Parlamento Europeo, interés marcado por el 11 de Setiembre (Paterlini y Vattimo, 2006, pp. 189 y ss.). Esta inclinación se ha intensificado desde entonces hasta hoy, para pasar la hermenéutica nihilista a ser virtualmente una filosofía política de y para la izquierda, como se halla confirmado en su obra más reciente, Essere e dintorni (Vattimo, 2018). 
Essere e dintorni es como una síntesis y, en cierto sentido, una reiteración del recorrido intelectual de los últimos tres lustros del autor con la pretensión de ser, en efecto, una filosofía política democrática interesada en la comprensión (y la promoción) de la izquierda.

El pensamiento "heideggeriano de izquierda" se basa en un diagnóstico histórico y social inicial de las democracias capitalistas liberales en cuyo ámbito resulta ser el autor parlamentario. La izquierda y la democracia son entendidas, en clave hermenéutica, antes como una experiencia que como un concepto tal o cual. Se trata, pues, del diagnóstico del mundo capitalista democrático, como no lo pudo haber sido antes del fin de la Guerra Fría, así como un diagnóstico de su hegemonía fáctica tanto europea como global. El turinés reitera después de 2004 tópicos recurrentes del periodo anterior sobre una supuesta homogeneización y banalización de la política como "falta de emergencia" (es decir, como ausencia de movimientos sociales y motivaciones para grandes cambios revolucionarios), que se habría ido gestado en las sociedades liberales, en especial después de la caída del Muro de Berlín. El espacio de la "nueva koiné", donde el Ser es lenguaje, le parecía en general al autor antes de 2001, y era deseado y expuesto como nihilismo deseado (Rivera, 2017, pp. 60-61; Vattimo, 2000, pp. 1-17).

El "heideggerianismo de izquierda" expresa un giro en las obras a partir de 2003, desde la promoción comprometida con la democracia entendida como nihilismo al cuestionamiento de la "falta de emergencia", es decir, al inmovilismo social, que en opinión de Vattimo encerrarían las sociedades liberales; en 2011, junto con Zabala, llamará a este inmovilismo "democracia metafísica" o "democracia emplazada" (cap. 1). Este giro desde la adhesión hasta la crítica puede observarse fácilmente en diversos ensayos pequeños y artículos de prensa desde la década de 1990, que concluyen marcados por el atentado contra las Torres Gemelas de Nueva York de 2001; este episodio daría lugar al título de su lección de despedida de la enseñanza de 2007 de la Universidad de Turín, "Del diálogo al conflicto" (2010). De este modo, el paso de una hermenéutica de izquierdas centrada en la dimensión "del diálogo" a un heideggerianismo en busca de "la emergencia" o "el conflicto" es también una reflexión sobre la democracia liberal desde la "emergencia" y el conflicto del atentado contra las Torres Gemelas (Rivera, 2015).

En efecto, el 11 de setiembre de 2001, un gran acto de violencia puso en "emergencia" a Nueva York; no se trataba de nada parecido a un diálogo, una nueva koiné para entendernos entre todos o una manera débil de pensar en cosas otrora de gran importancia moral o social. Este episodio de "emergencia", seguido de un largo proceso de inestabilidad global, hacía poco viable la retórica estetizan- 
te del Vattimo de 1985 o 1991, que llegó hasta La sociedad transparente. Aunque el turinés no lo reconociera, a partir de entonces toda retórica nihilista, suya o de otro, se hizo problemática; comenzó a ser algo decepcionante considerar "llamado del Ser" a la misma vez al mundo débil de las redes sociales, al pensamiento de izquierda dentro de ese mundo de presunta comunicación universal y, además, a todo el gran problema, para nada débil ni koiné de hacer una hermenéutica de la violencia que, de hecho, se padeció en 2001 y sigue desde entonces padeciendo el mundo y la Europa de la que Vattimo fue diputado.

Hasta 2001, Vattimo había sostenido que la hermenéutica y la democracia iban de la mano con una reducción paulatina de la violencia, que consideraba desde una lectura ontológica (como "debilitamiento del ser"). Como en 2001 se hizo evidente que esta crítica podía considerase cómplice de desencadenar la violencia social en lugar de disminuirla, Vattimo pasó de la promoción de la democracia como parte de la "nueva koiné" a la crítica de la "falta de emergencia" dentro de la democracia (Vattimo y Zabala, 2011, pp. 25-28, 84 y ss.); ahora la violencia política es democrática y se halla justificada si es no metafísica. En esta perspectiva, el pensamiento "heideggeriano de izquierda" se situaba como la voz de los silenciados de la historia, en oposición a la narrativa liberal o "pensamiento único": "el pensamiento único en el que estamos inmersos" (Vattimo y Zabala, 2011, cap. 1; Vattimo 2010, p. 28).

Vattimo fue desarrollando un pensamiento político con el propósito explícito de validar la vigencia del discurso de izquierda como "emergencia del Ser"; la versión abreviada de esta postura, cuyas consecuencias para el pensamiento de la democracia no han sido hasta hoy objeto de crítica, se resumen en el folleto Esperando a los bárbaros (2014).

El punto de partida es la interpretación de la realidad social y política propia del pensamiento único, es decir, la hegemonía ética del liberalismo tanto político como económico, a través de un engranaje fundamental: las pretensiones de universalidad del mundo social posterior a la Guerra Fría (Vattimo y Zabala, 2011, pp. 85 y ss.). El pensamiento único ejerce violencia metafísica e impide la "emergencia" de los invisibles y los vencidos; los bárbaros, sean estos quienes fueren y sea de donde sea que vengan, pueden, en cambio, ejercer violencia en o contra el mundo del pensamiento único en la precisa medida en que esta violencia no sería parte de la metafísica, sino un llamado del Ser para debilitar más las instituciones y la sociedad "metafísica". 
El mundo de las democracias, cuya violencia ha sido diagnosticada, sería consecuencia del despliegue tecnológico; en este sentido, tomando el término de Heidegger, el mundo democrático se denomina Ge-Stell (Vattimo, 2018, caps. 6 y 10; Woessner, 2017). En el Ge-Stell, la hermenéutica adquiere una cierta categoría ética universal como interpretación hegemónica comprometida con la izquierda. Justamente, la posición de Vattimo puede ser dicha "heideggeriana" de izquierdas porque sitúa el pensamiento de estas izquierdas dentro del diagnóstico Ge-Stell. Como ya hemos anotado, la interpretación filosófico política predominante del Vattimo anterior a 2001 identificaba las agendas de izquierda con las consecuencias sociales e institucionales de las nuevas tecnologías de la comunicación dentro de las democracias; ahora la retórica de la izquierda como "emancipación" supone, entonces, un espacio social exterior al Ge-Stell, que Vattimo ha asignado, esta vez con un uso algo exagerado de un pequeño ensayo de Walter Benjamin, a los "vencidos" o a los "invisibles" de la historia. Esta retórica de "izquierda" como pensamiento de los "vencidos" es transversal a la filosofía de Vattimo; puede ser rastreada desde la década de 1980 en trabajos tempranos como Ética de la interpretación o El fin de la modernidad (1986, p. 16).

La vocación de izquierda se agrega en "emergencia" contra las pretensiones de universalidad de la hermenéutica como lectura hegemónica en el Ge-Stell. La formulación emblemática del pensamiento hermenéutico político de Vattimo se halla en la obra conjunta con Santiago Zabala Hermeneutic communism (Vattimo y Zabala, 2011, cap. 1). El autor apuesta por una (nueva) democracia como proyecto de izquierda y aun de comunismo, en oposición a lo que se ha llamado desde entonces, con expresión de Zabala, framed democracies, democracias emplazadas o instaladas, es decir, las democracias exitosas inmersas y estables en la "falta de emergencia". El nudo central de por qué el heideggerianismo tiene "el destino" de ser de izquierdas y no socialdemócrata, monárquico o alguna otra cosa es el recurso que termina en un argumento voluntarista: todo pensamiento se postula, es postulado por y desde un interés; lo que cuenta, en último recurso para una interpretación del mundo social, es que ese interés sea producto de un acto voluntario, depende de una "elección" personal (Vattimo, 2010, p. 29).

En un enfoque voluntarista, estamos ante una prioridad del interés voluntario, el anhelo por la emancipación de una, podríamos decir, voluntad de emergencia, "un destino", "no legible en términos de valores y esencias universales" (Vattimo, 2010, p. 29). Este es el nudo argumentativo del libro De la realidad (Vattimo, 2012). Siempre se trata de sostener la posición política de Vattimo como una vocación o un llamado que uno siente y del que es responsable; esto explica que el ejemplo de caso del que se sirva para justificarse a sí mismo sea la elección de 
Heidegger por el nacionalsocialismo, como sucede en Esperando a los bárbaros (Vattimo, 2014, pp. 51-52, 58-60) en calidad de "un tipo de sabiduría" que no se puede explicar (p. 49). En la Lección de despedida, se sostiene lo mismo, con el añadido de una "elección" de las preferencias que se tiene (que tuvo Heidegger con Hitler o puede tener Vattimo con el populismo latinoamericano) como "apelación al y del Ser", pero, ciertamente, como "sabiduría" inexplicable del que se siente involucrado en ese llamado. Dice Vattimo:

En el caso de Heidegger, se trata conscientemente de una elección, de un tomar parte por, asumida como correspondiente a un destino específico, el del pueblo alemán, destino que es visto como una apelación al y del Ser, precisamente de un ser que se anuncia solo como determinado envío histórico en el marco de una situación [...] no legible en términos de valores y esencias universales (Vattimo, 2010, p. 29).

Esta postura facilita comprender el aparente abismo que hay entre las agendas políticas de Vattimo y la cuestionable consecuencia con sus presupuestos filosóficos, una crítica no tan infrecuente (Rivera, 2017; Uribe, 2009). Esta conclusión, sin embargo, afecta la comprensión que se puede tener de la democracia, palabra cuyo uso, como ya hemos visto, el mismo Vattimo cuestiona al identificarla con el Ge-Stell y, por lo mismo, con la supuesta violencia metafísica, primero en Ecce comu y luego en la obra conjunta con Zabala de 2011, abreviada ahora en Essere e dintorni, de 2018. Esto nos conduce a preguntarnos si hay un modelo de democracia que fuese permeable al anarcocomunismo hermenéutico.

Vattimo postula que los agentes políticos pueden proceder del mundo exterior al Ge-Stell, que los invisibles o los débiles no se hallan en relación de propiedad en el mundo de las democracias emplazadas y que, por lo mismo, se relacionan con estas como "emergencia", violencia justificada éticamente por no proceder del medio de la violencia, el Ge-Stell. En un motivo conocido tomado originalmente de un poema de Constantino Cavafis, Vattimo apela a la llegada de los bárbaros a la ciudad ordenada; en ella, todo es comprensible y transparente, conceptualmente hablando, y los bárbaros aparecen ante ella como invisibles, los vencidos, los débiles, etc., vale decir, los que la ciudad no contempla (Vattimo, 2014, pp. 66 y ss.; 2009a, p. 122; Rivera, 2015). Los bárbaros vienen de fuera de la ciudad y la conmueven. La ciudad debe identificarse, en opinión de Vattimo, con el ideal de la democracia liberal de pensamiento único, a la que caracterizaremos como una comunidad liberal de diálogo (2009a, pp. 117, 121-122), es decir, con la "democracia metafísica". El diálogo es el límite de lo que es posible en la ciudad y los bárbaros, al invadirla, transgreden ese límite. De pronto, los extraños, los 
de fuera, emergen como la verdad más fundamental del ámbito político, pues acontecen en él desde fuera como "la emergencia", una violencia que inauguraría y daría sentido al diálogo liberal (Rivera, 2009; Vattimo, 2012, pp. 217 y ss.; Vattimo y Zabala, 2011, pp. 19-28).

Como es notorio, se trata de admitir un esquema de "emergencia" violenta en que la democracia deja de estar adecuadamente descrita si la caracterizamos como una comunidad de diálogo. Esto exige aproximarnos a la concepción de la democracia que podría tener Vattimo.

\section{Vattimo y la democracia}

"La democracia, ¿pero cuál democracia?", escribía Vattimo en marzo de 2004, en el artículo de prensa "El comunismo recobrado", mientras rompía el carnet del Partido de los Comunistas Italianos (2009a, p. 45). Respecto del concepto o término democracia, en Vattimo ha tenido básicamente dos usos, que no siempre pueden ser diferenciados. Uno es el uso ordinario, el de los lenguajes sociales que él mismo usa en diarios, entrevistas y magazines. El otro es el que se desprende básicamente de Ecce comu, Hermeneutic communism y Esperando a los bárbaros. A esta lista se debe agregar Fundamentalismo democrático e dialettica del pensiero (2007) en favor del populismo y Addio alla verità (2009b). El primero ratifica y condensa la crítica a la democracia como pensamiento único y Ge-Stell; el segundo trató de dar forma más filosófica a la argumentación de Vattimo (2009b, pp. 18 y ss.; Uribe, 2012). A todos estos se suma Essere e dintorni (2018).

Habremos ahora de realizar un par de operaciones metodológicas. La primera será establecer un corpus de textos que sea manejable y representativo. La segunda será restringir nuestras observaciones al material conceptual que este mismo corpus contiene, para impedir las mismas esperables vaguedades y aporías que se desprenderían de no adoptar un corpus limitado.

El corpus consta de cuatro textos en los que se trata de manera explícita de la democracia, en un abanico temporal que va de 1990 a 2007, en que Vattimo publica en La Habana Ecce comu y Fundamentalismo democrático. Es en especial interesante este cuerpo de documentos, pues buena parte son los seleccionados por Vattimo y Zabala hacia 2003 para dar el giro definitivo a la hermenéutica nihilista como anarcocomunismo y heideggerianismo de izquierdas. El primero en orden cronológico es una conferencia dictada en Bogotá en 1990 que se titula 
"Hermenéutica, democracia y emancipación" (1996, pp. 47-64). El segundo son dos conferencias que consideramos complementarias: "Hermenéutica y democracia" de 1994 (Zabala, 2004, pp. 113-124) y "Filosofía y declinar del Occidente" de 1998 (pp. 39-55). El tercero es una colección de tres textos: "Subversivismo democrático", una conferencia en Lisboa de 2004 (2009a, pp. 46-54) y un par de artículos en prensa periódica (2009a, pp. 57-69).

Vayamos ahora a los textos de 1994 y 1998. Respecto de su nivel de abstracción, podemos comenzar con el segundo, "Filosofía y declinar en Occidente". En general, este ensayo podría ser calificado como un texto sobre política y racionalidad, de "reconstrucción de la racionalidad". La tesis central es que esto es necesario debido a la "disolución de la idea de que haya un significado y una dirección unitaria en la historia de la humanidad" (1998, p. 39). "Racionalidad", pues, es un término que se refiere al sentido de la historia y, dentro de ella, a las instituciones políticas fundadas en ese sentido disuelto. De la tesis central se deriva un cuestionamiento que resulta en especial interesante para nuestra reflexión sobre la democracia, a saber: si la "propia civilización" (la liberal) responde al "máximo nivel de evolución alcanzado por la humanidad" (1986, p. 39). Esto trae dos consecuencias. La primera es institucional: no tenemos ninguna razón para considerar que la democracia liberal fuera el mejor régimen político posible, "la perfección final". La segunda es política y se vincula con la tesis central: si no hay una dirección unitaria de la historia de la humanidad, entonces, es legítimo plantearse interpretaciones conflictivas de las instituciones que pretenden ser las superiores.

En "Filosofía y declinar del Occidente", Vattimo se plantea la presunta superioridad del régimen democrático liberal como "la cuestión de la universalidad" versus la "multiplicidad de visiones del mundo" (1998, pp. 46-47). Es evidente que el tema de fondo se plantea como la legitimidad politica de las identidades: "El hecho de que la pluralidad de visiones del mundo no es la convivencia pacífica", añade Vattimo, "sino que da lugar a conflictos" y "afirmaciones de pertenencia" que "esperan alguna indicación de la filosofía" (p. 47). Vattimo concluye con una reivindicación débil del Occidente desde el punto de vista de un programa de "ocaso" y "secularización". Se trata, sin duda, aunque de manera vaga y sin referencias, de una concepción "pluralista" de la democracia como opuesta o alternativa a la democracia metafísica o liberal. No en vano, el texto de 1998 concluye con "una explícita aceptación del mundo actual como lugar de identidades débiles y de dogmáticas liberales" (p. 51).

La "racionalidad" es reconstruida así sobre tres consideraciones: que no hay fundamento para la historia, que la experiencia de esa falta de fundamento es una 
liberación de interpretaciones en conflicto y que, como corolario de lo anterior, la aceptación de ese conflicto es un lugar inevitable de la comprensión de las instituciones políticas. Se trata de una reflexión de filosofía política a partir de las "afirmaciones de pertenencia" que dan "lugar a conflictos" en un contexto específico de interpretación, que es el "fin de la Historia". Esta experiencia es también la que sitúa el pensamiento de la hermenéutica en relación con la democracia (Giorgio, 2009, pp. 241 y ss.).

El texto de 1994 se titula "Hermenéutica y democracia". Como hemos adelantado, es un texto de sociología aplicada. Se trata de descubrir "una vinculación significativa entre los problemas de la hermenéutica filosófica y aquellos con los que se enfrenta la izquierda en nuestras sociedades democráticamente avanzadas". Ya sabemos de qué problemas se trata, el pensamiento único, "la situación de las democracias industriales avanzadas". Interesa que, en tratamiento específico de una concepción de la democracia, el nudo del problema es demostrar que "la hermenéutica" "refleja más fielmente el pluralismo de las democracias" (Vattimo, 2004, p. 113). Del texto anterior, sabemos que este pluralismo debe relacionarse con conflictos de identidades, comunidades o colectivos.

"Hermenéutica y democracia" se inicia con una caracterización de la hermenéutica en general como filosofía de la posmodernidad. Interesa el objetivo de esta definición, que está orientada a establecer qué clase de concepto de democracia se deriva de ella. La hermenéutica se define por dos características: la primera es la "despedida del fundamentalismo metafísico" y la segunda es la "concepción del mundo como conflicto de interpretaciones" (Vattimo, 2004, pp. 113, 116). Detrás de ambos postulados subyace este presupuesto sociológico: que hay "un pluralismo" "en el plano político" que "se expresa en la democracia". El lector sutil comprenderá rápidamente que se trata de una representación de las sociedades modernas que no se ajusta a la experiencia histórico-social de la década de procedencia del ensayo y que, por ende, es una definición estipulativa de la democracia. Se trata de lo que debe ser la democracia y no de lo que es. Vattimo postula un modelo de democracia que "se expresa" en "un pluralismo" que aún no existe, pero que debería existir. Las condiciones de ese pluralismo son las características básicas de la hermenéutica: antifundamentalismo y conflicto de interpretaciones.

Si leemos en orden las reflexiones que siguen a la definición general de la hermenéutica, confirmamos en el texto de 1994 que se da un traslado desde un ámbito estipulativo del pluralismo a uno descriptivo. Es a partir de este segundo plano que se habrá de dar cuenta de la clase "ideal" de democracia de Vattimo. Como veremos, el concepto central va a ser la idea de la "violencia" como punto 
de partida de la reflexión sobre el pluralismo, para pasar (por decirlo de alguna manera) del pluralismo real al pluralismo ideal. En efecto, las reflexiones que siguen expresan una tensión fáctica entre dos versiones sociales vigentes del pluralismo. Por un lado, habría un pluralismo individualista, basado en el modelo de las prácticas sociales de mercado: Vattimo lo llama "la cultura del supermercado". Por otro, habría un pluralismo "fundamentalista" cuya agenda sería "la recuperación de fundamentalismos de diversa especie" (2004, p. 114). Vattimo afirma luego que ninguna de las dos concepciones de las identidades colectivas hace posible el pluralismo tal y como él lo entiende. Pero, si no es a partir de uno de estos conceptos de identidad, uno debía preguntarse cómo entiende el Vattimo de 1994 la naturaleza del pluralismo. La respuesta del texto al principio puede resultar algo chocante. Esta se desarrolla apelando a lo que el turinés denomina "una filosofía de la historia", la conclusión de un proceso "nihilista" de consumación del ser metafísico; agrega, acto seguido: "es decir, de la violencia" (2004, pp. 117-118).

Por el momento, podemos prescindir del "proceso nihilista" para fijarnos en la violencia. Lo que importa es reconocer que, detrás de una retórica en que se asocian democracia y hermenéutica, subyace el presupuesto más básico de que hay que aceptar una violencia originaria, fundante, en torno a la cual el pluralismo se hace posible (Zabala, 2009, pp. 451-475). El pluralismo de la democracia no consiste en una violencia o en un conflicto, pero se entiende como un ámbito de la interpretación política porque es en su origen una violencia. Lo que la democracia debe ser para ser "pluralista" consiste en una aceptación de la violencia como referente de la vida política (Vattimo, 2004, pp. 122-124). Pero queda pendiente un punto. ¿Qué significa que la violencia se defina como "la conclusión de un proceso nihilista"? Pasemos a la conferencia de Bogotá de 1990.

“¿Cabe fundar una política democrática, de emancipación, o incluso, por decirlo más claramente, progresista y de izquierdas, en la hermenéutica?" (Vattimo, 1996, p. 47). Este es el tema de la conferencia de 1990, que es también la primera en la serie cronológica de textos de nuestro corpus de Vattimo. Al lector atento no se le escapa que el texto de 1990 es una versión más antigua del texto de 1994, por lo que irremediablemente hay una serie de tópicos que se repiten. Se trata, eso sí, y más claramente, de "fundar" la política (democrática) en la hermenéutica. La caída del Muro de Berlín es aún un hecho reciente. La pregunta retórica que encabeza el texto de 1990 sigue la misma secuencia que en 1994. Primero, hay una definición de la hermenéutica como antifundamentalismo y conflicto de interpretaciones (pp. 48-49), que luego se amplía y complementa con la misma idea de "una filosofía de la historia" "al final de un proceso nihilista" (pp. 55-59). Se concluye con un desarrollo de la idea de "violencia" como elemento fundante 
de la vida política, de tal modo que el "hilo conductor" de la democracia es su relación con esa "violencia" (p. 61). Sería deshonesto no anotar que explícitamente se indica que ese hilo conductor es "la reducción de la violencia", pero está sobrentendido que esa reducción, entendida como una acción humana, implica una violencia que es la que hay que reducir.

Es importante notar que la violencia aludida en 1990 no aparece como un hecho social, sino como un trasfondo hermenéutico histórico-político, es decir, ontológico. Este trasfondo es la "historia del Ser" o "el nihilismo" (Vattimo, 1996, pp. 56-57). Hay que entender estas expresiones como significando un proceso histórico que es la justificación de la democracia, su sentido, aquello en función de lo cual esta debe ser pensada como lo que es ahora. Este proceso histórico es el origen de la democracia, pero también lo es de la hermenéutica. En el texto de 1990, este doble origen en un solo proceso se explica como una relación de "homología" "entre filosofía y sociedad" (pp. 50 y ss.). A efectos de nuestro trabajo, esto significa que las características que se atribuye a la hermenéutica adquieren valor vinculante para la comprensión de la democracia. Nos indican lo que la democracia debe ser. Esta debe ser pluralista, pues la hermenéutica también lo es; pero no puede consistir solo en diálogo, pues la hermenéutica, como resultado de un proceso histórico, no es ella misma tampoco un diálogo, sino primera y definitivamente la historia de una violencia que ha devenido con el tiempo (en el "fin de la Historia") en un diálogo social.

Recapitulemos. En 1998, tenemos un texto que propone la "reconstrucción de la racionalidad" desde el horizonte de la hermenéutica. No es un tema abstracto, sino que se trata en realidad de una atención filosófica a un momento histórico, que es la hegemonía del "pensamiento único". Entonces, Vattimo concluye afirmando la necesidad de una aceptación explícita del programa de la democracia liberal. Pero sería un terrible malentendido interpretar este llamado a la aceptación como un mero aceptar. En realidad, se trata de una sentencia normativa (moral) que está basada en una experiencia histórica, en un diagnóstico cuyo núcleo conceptual es la idea de la Historia (y el fin de la Historia) como un acontecer desde la violencia. Esto se interpreta como historia del "ocaso", de "secularización", pero también de "fin de la metafísica" y "nihilismo". En este campo, en cuyo fondo se halla la violencia, esta se expresa como un conflicto de interpretaciones, esto es, como la experiencia de comprender que la actualidad se manifiesta como una violencia fundamental. La violencia es el campo del que no podemos librarnos, pero que es también un conflicto del que queremos salir a través del diálogo. 
Podemos pasar ahora al último grupo de textos que tenemos reservado para esta sección. El texto central es un artículo para La Stampa de 2004, una de cuyas características centrales es la insistencia en el tópico más general desde 1990: la aceptación de la democracia liberal en tanto "campo" efectivo del fin de la Historia. Esto quiere decir: la democracia liberal es el campo del conflicto de interpretaciones y, por tanto, es también el lugar propio de la hermenéutica. Pero, en 2004, hay un desplazamiento manifiesto del acento en la conflictividad. Ahora el fondo hermenéutico de violencia justifica la radicalidad de las respuestas en el campo del conflicto, es decir, interpreta la crítica ya como conflicto (social), como en la Lección de despedida, Hermeneutic communism y Essere e dintorni.

Hasta 1998, el acento de la reflexión es el carácter inevitable del campo, ese campo cuyos ocupantes son intérpretes que compiten, pero que lo hacen dialógicamente. Ahora Vattimo realiza él mismo el diagnóstico del fin de la Historia como pensamiento único y, por tanto, como fin de la política (2009a, p. 49; 1991, pp. 15 y ss.). La idea general es que, incluso dentro del campo de la democracia, el conflicto debe acentuarse como fundante, esto es, como la necesidad, derivada de la propia situación histórica, de reforzar los antagonismos, como "encontrar alguna manera revolucionaria de interrumpir el ciclo" (2009, pp. 49-50) y "enfrentar el fetiche de las reglas formales de la democracia" (p. 51); de ahí que dentro del campo democrático sea necesario agregar una (mayor) "dosis de subversivismo", esto es, de conflictividad. Se requiere "actos subversivos", que van, desde la apelación a la instancia religiosa para la resistencia, hasta los actos, en efecto, violentos. El diagnóstico no podría ser más explícito: "de otro modo la democracia misma resulta asfixiada" (p. 53).

El esquema general de interpretación de la democracia como homóloga con la hermenéutica, como interpreta el lector y hemos visto en las obras anteriores, no se ha modificado en 2004. Solo se ha acentuado el valor (normativo) del "conflicto de interpretaciones", que es una función propia de la hermenéutica nihilista. No debe sorprender, pues, que más adelante, en la sección que sigue de la compilación que incluye el artículo de 2004, la referencia de fondo de la concepción pluralista de la democracia se emparente con un clima de interpretación política que insiste en la idea de que la democracia es más el conflicto que el diálogo.

La perspectiva del campo acentúa su carácter de consumación y final desde el punto de vista de la recuperación del espíritu revolucionario, que se desplaza ahora de manera retórica al Heidegger cuyo pensamiento termina siendo el "riesgo que debemos correr". Vattimo se expresa desde el punto de vista de recuperar un cierto "espíritu apocalíptico". "No debería avergonzarnos pensar nuestra situación 
en términos apocalípticos" que nos "hace capaces de legitimar la recuperación de una palabra de "izquierda" como revolución" (p. 61). Este tópico fue retomado una década después sin mayor diferencia, solo que ya en la retórica de la "falta de emergencia" y otros elementos retóricos trabajados con Zabala en 2011 (2014, pp. 50-56, 67-68).

\section{En torno a Chantall Mouffe}

En la postura general de Vattimo, tanto como en el examen detallado de sus textos reimpresos desde 2003 hasta la actualidad, constatamos la insistencia en sostener que, ante la "falta de emergencia" del Ge-Stell, y su ámbito de violencia metafísica, una hermenéutica nihilista "de izquierdas" debía ver con interés la irrupción de los bárbaros; estos bárbaros serían en algún sentido demócratas, habiendo concedido que su violencia es legítima porque es una forma democrática de hacer violencia no metafísica (Vattimo, 2018, cap. 1). Hay aquí una aporía: combatir la violencia metafísica del Ge-Stell con otra violencia de los "invisibles", etc. Esta aporía puede resolverse a nuestro juicio si, en lugar de valerse directamente de la retórica de Vattimo ("emergencia", "conflicto", "violencia metafísica", "democracia emplazada", etc.), usáramos otros medios.

En este apartado, nuestro propósito es sugerir que el pensamiento político de Vattimo corresponde con aspectos centrales de la democracia "radical", que, en tiempo no tan reciente, han desarrollado Laclau y Mouffe (1985). Esto es interesante porque ofrece una manera de concebir la democracia desde un ángulo que privilegia conceptos equivalentes a "emergencia" o "conflicto" con el mismo esquema crítico de Vattimo contra el pensamiento único. Como es bien sabido, la propuesta de Mouffe y Laclau es una formulación de las teorías de la democracia que se conocen como "pluralistas", en una tradición que hay que retrotraer al politólogo Robert Dahl (1991). Una posición "pluralista" de la democracia es aquella en que las instituciones democráticas deben convivir políticamente con formas altamente críticas de sus propios presupuestos. En particular, esta desea distinguirse de otros modelos de democracia que no lo hacen, en particular la democracia "liberal", bajo cuyo rótulo, siguiendo a Mouffe (2007, p. 17), vamos a agrupar toda forma no pluralista de entender la democracia.

Complementaremos este acercamiento con una breve reflexión teórica propia sobre las identidades en función de las cuales es tanto posible el pensamiento del diálogo como del conflicto. 
Para nuestros objetivos, vamos a recoger algunos motivos argumentativos. Estos motivos configuran un ámbito conceptual y comprensivo favorable para orientar y dar sentido al pensamiento político de Vattimo. Esto se debe a que corresponden con esferas de sentido compartidas por ambos autores.

El primero y el más importante de los motivos argumentativos en la teoría de la democracia de Mouffe en 2004 atiende a la concepción de la naturaleza de la racionalidad de los fenómenos políticos. Se trata de un paradigma del que Mouffe participa con otros teóricos de la democracia pluralista (como John Gray, Isaiah Berlin, Joseph Raz, Michael Walzer, entre otros). El segundo atiende a la naturaleza de lo político según Mouffe; en él, la argumentación sobre la racionalidad en la comprensión de la democracia desemboca en una definición hermenéutica de lo político (Greppi, 2006, 139 y ss.). El tercero se refiere a lo que parece ser el problema central de la democracia, a saber: su relación con el otro (eventualmente no democrático) que parece existir en su seno; por ejemplo, con el fundamentalismo religioso o con concepciones políticas incompatibles con el régimen estandarizado de democracia liberal (García y Tortella, 2008, pp. 225 y ss.). El cuarto se refiere a lo que podríamos llamar "el aspecto narrativo" de la democracia pluralista, es decir, su justificación en los lenguajes sociales.

Comenzamos con la concepción más general de la racionalidad. La democracia pluralista se define por oposición: en este caso, frente a versiones que podemos llamar racionalistas o metafísicas de la democracia que, en general, Mouffe (2004, p. 17) identifica con el liberalismo, es decir, las framed democracies, la "democracia metafísica" de Vattimo y Zabala. Un punto de partida básico de las versiones metafísicas de la democracia es la pretensión de ser un modelo intrínsecamente superior de organización política humana. El rechazo del carácter metafísico de las framed democracies se refiere a la idea general de la pretensión de que haya fundamentos epistémicos o racionales para la democracia metafísica. Quizá podríamos agregar que la crítica del pluralismo a la democracia metafísica puede resumirse como un escepticismo o un pesimismo frente a la idea del carácter irreversible tanto de la democracia misma como del proceso histórico que ha dado lugar a las instituciones democráticas de la actualidad. Pero esto implica también una concepción alternativa de la racionalidad política, que no puede ser racionalista ni metafísica, y que debe desconfiar más de la presunta superioridad intrínseca de las instituciones hegemónicas del presente.

Debemos anotar que la crítica de los modelos al uso de democracia por Mouffe corresponde con una concepción de la racionalidad hermenéutica, que atiende a la interpretación de los hechos históricos tanto como a los presupuestos más 
elementales de la experiencia humana, algo que ahora llamaríamos una "ontología política", como han notado Etchegaray (2011) y Milla (2013). Un aspecto novedoso del enfoque de Mouffe es que lo político es pensado con anterioridad a cualquier forma determinada de régimen político, incluso la misma democracia, y no tiene por objeto, por tanto, fundamentarla racional, científica o metafísicamente (Etchegaray, 2013, pp. 6-7). Estamos ante una prioridad conceptual, no normativa; esto es lo opuesto a lo que ocurre en la argumentación ordinaria de los teóricos y los filósofos políticos que se ocupan de ella. Mouffe no solo hace teoría política, también hace hermenéutica y ontología política. Veamos ahora cuáles son las fuentes de este enfoque.

A efectos de nuestra argumentación, interesa subrayar una doble fuente de la manera en que Mouffe enfoca la democracia pluralista: Carl Schmitt y Martin Heidegger. En orden conceptual, la fuente más básica procede de Schmitt, autor de la distinción amigo/enemigo, que el jurista alemán desarrolló en El concepto de lo político, cuya versión definitiva es de 1932 (2002). Schmitt propuso en esta obra que la distinción amigo/enemigo era una condición necesaria para el pensamiento de lo político, esto es que, en ausencia de esa distinción, "lo político" es impensable (pp. 55-56). La distinción amigo/enemigo constituiría así la esencia de lo político (Zarria y Maschke, 2019, pp. 269-270), lo cual calificaría para hacer de esta distinción un a priori y, por lo mismo, una característica ontológica de la experiencia humana. En efecto, Mouffe asocia lo anterior con una distinción ontológica que utilizó Martin Heidegger en Sein und Zeit con la retórica de los existenciarios como condiciones necesarias para la experiencia histórica (Vattimo, 2006 , pp. 32 y ss.). Con esto, es posible interpretar la distinción amigo/enemigo de Schmitt como una característica necesaria y presupuesta de la comprensión de la experiencia política en la historia humana de todo régimen político posible, incluyendo allí la democracia.

Nos sea concedido el perdón de los especialistas para lo siguiente. Heidegger hace una distinción entre dos tipos de características de la experiencia humana. Unas que encontramos como condiciones necesarias y otras que encontramos, en cambio, como contingentes. En este esquema abreviado de Heidegger, las segundas se subordinan a las primeras, lo cual quiere decir que las segundas son incomprensibles en ausencia de las primeras. Si aplicamos esta distinción de Heidegger a la experiencia de los lenguajes políticos, encontramos dos planos: un plano "ontológico" y otro "óntico", respectivamente (Vattimo, 2006, pp. 82 y ss.). La esencia de lo político y la gramática más básica de los lenguajes sociales en torno a lo político serían ontológicas, pero no en cambio las formas de régimen político, 
que serían ónticas; en palabras de Mouffe (2004), "lo ontológico tiene que ver con el modo mismo en que se instituye la sociedad" (pp. 15-16, 23).

Aplicado lo antedicho a la racionalidad de la democracia, lo que se sugiere es que sus características como un régimen político distinto de otros son ónticas y, por lo mismo, completamente contingentes, de ninguna manera ligadas a la "esencia" de la condición humana, es decir, a nada de índole "metafísica". Todo en la democracia es óntico, nada es ontológico (Mouffe, 2004, p. 16). Si alguien tiene preferencias por un régimen democrático real y tiene interés en que subsista, no deberá considerar la democracia en busca de un fundamento epistemológico, de validez o de condiciones ideales que la justifiquen, como hacen los filósofos metafísicos, sino desde el ángulo de la distinción amigo/enemigo. Lo que verdaderamente cuenta para la democracia no es cómo se fundamenta, sino más bien cómo es capaz de relacionarse con su/s enemigo/s reales.

En este punto, nos conviene insertar el contexto histórico social que da lugar a las reflexiones de Mouffe, lo que va a originar que invirtamos el orden de los dos motivos siguientes. Se trata del referente que hace de la ontología política de Mouffe una hermenéutica: lectura de la actualidad. Como la referencia a Mouffe atiende un texto de 2004, es inevitable referir los dos motivos anteriores a experiencias sociales de la época de composición del texto, que dan un sentido peculiar a la idea de "democracia pluralista" que estamos esbozando y que al lector le recordarán también el contexto de la retórica de las framed democracies y el Ge-Stell en Vattimo. La más relevante es la vigencia social de lo que se ha llamado desde la década de 1990 "pensamiento único". Para el pensamiento único, el mismo que para Vattimo se identifica con la democracia liberal y el Ge-Stell, interpretaba para 2004 que había un solo proceso histórico global del cual el triunfo del liberalismo planetario sería la consecuencia tanto económica como política; este proceso sería el mismo del Ge-Stell, y debía soldarse en un solo horizonte con las nuevas tecnologías de la comunicación y el internet. Como agudamente menciona Mouffe, este diagnóstico optimista puede reconocerse en todos los autores de filosofía política que secundan el liberalismo en el mismo periodo, sea o no a través de una estrategia metafísica, desde Jürgen Habermas hasta Richard Rorty (pp. 89-96). Por lo demás, es un hecho palmario que no hay comunicación conceptual auténtica entre la universalidad racional (moral) y el fenómeno de la globalización económica e informática, como había notado antes Karl-Otto Apel (1999, pp. 7-8). Es fácil observar que esto coincide con el horizonte de "falta de emergencia" en el mundo social del pensamiento único denunciado por Vattimo en las democracias metafísicas o emplazadas. 
Del carácter presuntamente inevitable del pensamiento único se infería una agenda también única desde el punto de vista de las instituciones políticas y creencias, las del liberalismo. Pero esto tenía consecuencias graves respecto de la definición más esencial de lo político. Mouffe (2004, cap. 3) las elaboró con énfasis en contraste con el pensamiento de los sociólogos de tendencia socialdemocrática Anthony Giddens y Ulrich Beck. La fusión entre el programa liberal y la globalización permitía suponer que las discontinuidades o ineficacias del mundo social metafísico se incorporarían a un programa racional de negociaciones universales, facilitadas por las tecnologías de la comunicación, como era, dicho sea de pasada, la esperanza en La sociedad transparente (1989). De este modo, la realidad social de un "pensamiento único" implicaba que se había producido el fin de los antagonismos globales y el fin de la Historia (que es la historia de estos antagonismos). La distinción entre "izquierda" y "derecha" dejaba de ser relevante (Mouffe, 2004, pp. 12 y ss.).

Con la ilusión de que no había ni habría nunca ideologías alternativas al pensamiento único, este se impuso a modelos de democracia metafísicas, epistémica o deliberativa (Carlos Santiago Nino, Jürgen Habermas, Anthony Giddens), cuyo motivo principal podemos tipificar como la conmensurabilidad potencial de todas las diferencias a través de prácticas de diálogo. Al inicio, tenemos el fin de la Guerra Fría, lo que Miguel Giusti, un filósofo liberal de Lima, hubo calificado alguna vez de "la marcha triunfal del liberalismo en el mundo" (2006, p. 238). La política era definida, entonces, como diálogo y el problema filosófico y de teoría política más fundamental era establecer las condiciones y los procedimientos para el consenso de ese diálogo (Hernando, 2000, cap. 6). Este escenario hubiera permanecido sin mayor dificultad si algunos hechos más o menos terribles no hubieran dado motivo de sospecha de que algo andaba mal.

Hagamos referencia solo a los hechos de la política internacional. El que haya en la actualidad regímenes externos diversos y aun antagónicos de la democracia liberal destaca la terrible sugerencia hermenéutica de que es también posible que exista o pueda existir un descontento interno en las propias democracias liberales, un descontento que escape a la idea de un diálogo conmensurable atendido por prácticas de procedimientos de consenso. En este panorama histórico, resulta tentador pasar de modelos universalistas, metafísicos de democracia, a otros que resulten más ajustados a las sugerencias de la realidad. Pero entonces hay que pasar de la racionalidad del diálogo de intereses conmensurables a un tipo de racionalidad en la que sea posible pensar, no solo en el diálogo, sino también en el conflicto. Esta sugerencia de Mouffe y la democracia radical es un elemento fundamental para entender el diálogo con los bárbaros de Vattimo. 


\section{Conclusiones}

Hemos intentado plantearnos la cuestión de la democracia dentro del discurso de la hermenéutica nihilista de Gianni Vattimo. En principio, se trata de una aplicación del discurso hermenéutico a cuestiones políticas y sociales, como sabemos, soslayadas por el autor hasta 2001, un punto de referencia para su giro político. Exponiendo la trayectoria del autor en esta materia, comprobamos dos cosas. La primera, lo que podríamos llamar una estructura retórica, la posición heideggeriana de izquierdas, comunismo hermenéutico o anarcocomunismo. Hemos mostrado que el aspecto "de izquierdas" corresponde más a una vena voluntarista, ocasionalmente amparada en referencias a Nietzsche, que a un más genuino desarrollo conceptual. En principio, no hay nada que haga de la hermenéutica en su versión nihilista una posición de compromiso político tal o cual. Heidegger se comprometió con el nazismo, Vattimo lo hace con el populismo chavista, quizá otro tenga adhesiones igual de intensas con la teocracia islámica o la monarquía constitucional. Pero esto sirve de curso para el tema central: el rol y el sentido de la hermenéutica con una agenda de izquierdas dentro (y no fuera) del régimen de las democracias, el pensamiento único o como se quiera denominar el mundo del cual Vattimo fue dos veces eurodiputado.

En los textos académicos de Vattimo dedicados a la filosofía política, desde Nihilismo y emancipación hasta Essere e dintorni, encontramos una aporía entre una exigencia de intensificar o hacer más auténtica la experiencia democrática, por un lado, y adoptar un diagnóstico apocalíptico de esta (Vattimo, 2014, pp. 13 y ss., 56 y ss.) como framed democracy, en que la democracia capitalista liberal sería la forma institucional de la "falta de emergencia" dentro del Ge-Stell (Vattimo y Zabala, 2011, cap. 1; Vattimo, 2018, cap. 1), por lo que sería, en sí misma, una forma opresiva, "un nuevo fascismo" (Vattimo, 2014, p. 70). Este diagnóstico identifica, además, la democracia formal o real (Vattimo, 2009a, pp. 57 y ss.) como el ámbito de batalla en que "los invisibles", "los bárbaros", etc., tendrían legitimidad para ellos actuar políticamente y hacer por su propia mano "la emergencia"; actuarían esta "emergencia" como respuesta contra la supuesta violencia de la democracia metafísica o emplazada (Vattimo, 2018, cap. 1, p. 16). En este contexto, el anarcocomunismo o posición heideggeriana de izquierda no parece ya solo una postura cuestionadora de la democracia sino, mucho más bien, su enemiga.

Hemos querido acercar y contribuir a la reducción del antagonismo entre la emergencia y la violencia metafísica del Ge-Stell realizando lo que ahora podemos designar como una cirugía antivoluntarista. Su principal ventaja sería sustraer el aspecto apocalíptico de la voluntad de izquierda en la idea de conflicto para 
adoptar una estrategia sustraída de la democracia pluralista en la versión radical de Chantall Mouffe: esta consiste en incorporar y aun fomentar versiones altamente conflictivas tanto fuera como dentro del régimen democrático, cosa que es posible incorporando la distinción amigo/enemigo de Carl Schmitt, esto es, sumar la idea de que a veces no solo el diálogo sino también el conflicto puede ser una condición hermenéutica para comprender la democracia.

Apartándonos un poco de Mouffe y Schmitt, hemos incorporado la idea de la democracia como una identidad débil, es decir, como una referencia de identidad que es cauta con sus límites y es generosa con los conflictos que realmente tiene para, en los hechos antes que en la teoría, incorporar los conflictos sociales bajo la conciencia de su reconocimiento. En un repaso de los textos sobre hermenéutica y democracia que Vattimo recicló de su periodo anterior (1990-1998), hemos entrevisto tanto su cercanía con nuestra propuesta a partir de Mouffe como la falta de herramientas para hacer del conflicto algo que no sea una amenaza deseada a la convivencia democrática, tal y como hoy la conocemos.

\section{Referencias}

Apel, K-O. (1999). La globalización y la necesidad de una ética universal. Erasmus. Revista para el diálogo intercultural, 1(1), 7-28.

Colombo, A. (2001). Democracias sin fundamento. Trama Editorial/ Prometeo.

Dahl, R. (1991). Democracy and its critics. Yale University Press.

Etchegaray, R. (2011). La ontología política de E. Laclau y Ch. Mouffe. En

Nuevo Pensamiento. Revista de filosofía política, 1(1). https://dialnet.unirioja.es/servlet/ articulo?codigo $=5513817$

García, L. y Tortella, G. (2008). Juventud y fragilidad de la democracia. Juventud y fragilidad de la democracia. En L. A. García Moreno y G. Tortella (coords.), La democracia ayer y hoy (pp. 225-234). Gadir.

Giorgio, G. (2006). Il pensiero di Gianni Vattimo. L'emancipazione dalla metafisica tra dialettica ed ermeneutica. Franco Angeli.

Giorgio, G. (2009a). Nihilismo hermenéutico y política. En C. Muñoz Gutiérrez, D. M. Leiro y V. S. Rivera (coords.), Ontología del declinar: Diálogos con la hermenéutica nihilista de Gianni Vattimo (pp. 241-254). Biblos.

Giorgio, G. (2009b). La portata politica del 'pensiero debole' di Gianni Vattimo. Trópos, 2(1), 113-125. http://www.giorgiogiovanni.it/wp-content/uploads/2009gLa-portata-politica-del-pensiero-debole-di-G.-Vattimo.pdf

Giusti, M. (2006). Tras el consenso. Entre la utopía y la nostalgia.

Dyckinson.

Greppi, A. (2006). Concepciones de la democracia en el pensamiento político contemporáneo. Trotta. 
Grijalba Uche, M. (2018). Hacernos cargo de los débiles. El regreso del pensamiento libertario y comunista como expresión del comunismo. Pensamiento al margen. Revista digital, 73-88, 241-254. https://dialnet.unirioja.es/servlet/articulo?codigo=6804271

Grondin, J. (2008). ¿Qué es la hermenéutica? Herder.

Hernando, E. (2000). Pensando peligrosamente. El pensamiento

reaccionario y los dilemas de la democracia deliberativa. Pontificia Universidad Católica del Perú.

Laclau, E. y Mouffe, Ch. (1985). Hegemony and socialist strategy. Towards a radical democratic politics. Verso.

Leiro, D. M. (2007). Gianni Vattimo. El último comunista. Utopía y Praxis Latinoamericana. Revista Internacional de Filosofía Iberoamericana y Teoría Social, 12(39), 143152. https://dialnet.unirioja.es/servlet/articulo?codigo $=2526189$

Llorente, J. (2016). ¿Puede la hermenéutica nihilista de Gianni Vattimo justificar racionalmente sus últimas posiciones políticas? Las torres de Lucca: Revista internacional de filosofía política, 5(8), 185-226.

Miller, T. H. (2009). In Hermeneutic Circles. A Reply to White. Political Theory, 37(6), 817822. https://doi.org/10.1177/0090591709345466

Milla, R. (2013). Emancipación de la metafísica. Hermenéutica política en Gianni Vattimo. Revista Preseitas, 1(1), 102-135. https://www.redalyc.org/pdf/4989/498951551003. pdf

Mouffe, Ch. (2007). En torno a lo político. Fondo de Cultura Económica.

Paterlini, P. y Vattimo, G. (2006). Non Essere Dio. Un'autobiografia a quattro mani. Aliberti.

Rivera, V. S. (2005). Ilave: El terror como reconocimiento. Socialismo y Participación, 99, 87-98.

http://revistasolar.org/wp-content/uploads/2020/06/SOLAR-2-33-48.pdf

Rivera, V. S. (2009). Ex Oriente salus! Pensar desde el margen. En C. Muñoz Gutiérrez, D. M. Leiro y V. S. Rivera (coords.), Ontología del declinar. Diálogos con la hermenéutica nihilista de Gianni Vattimo (pp. 311-334). Biblos.

Rivera, V. S. (2015). Hermenéutica y violencia. Reflexiones a partir de Comunismo hermenéutico de Gianni Vattimo y Santiago Zabala. Ideas y valores, 54 (158), 316-336. https://doi.org/10.15446/ideasyvalores.v64n158.51120

Rivera, V. S. (2017). El fin del pensamiento débil. Gianni Vattimo: Nihilismo y violencia global. Estudios filosóficos, 66(91), 59-84.

Schmitt, C. (2002). El concepto de lo político. Alianza.

Ugarte, F. J. (1998). Filosofía, política, religión: Más allá del pensamiento débil, de Gianni Vattimo. Teorema: Revista internacional de filosofía, 17(3), 141-143. https://dialnet. unirioja.es/servlet/articulo?codigo $=4352206$

Uribe, L. (2009). Hermenéutica y nihilismo: Hacia un pensamiento del conflicto en Gianni Vattimo. Hermenéutica Intercultural: Revista de Filosofía, 18-19, 171-181.

https://dialnet.unirioja.es/servlet/articulo?codigo $=7364891$

Uribe, L. (2012). "Addio alla verità" Gianni Vattimo Ed. Meltemi, Roma, Italia,

2009, 143 Páginas ISBN: 978-88-8353-648-9. Hermenéutica Intercultural: Revista de Filosofía, 20-21, 237-239. https://dialnet.unirioja.es/servlet/articulo?codigo=7364906

Vattimo, G. (1986). El fin de la modernidad: Nihilismo y hermenéutica en la cultura posmoderna. Gedisa.

Vattimo, G. (1989). La società trasparente. Garzanti. 
Vattimo, G. (1991). Ética de la interpretación (Teresa Oñate, Trad.).

Paidós.

Vattimo, G. (1996). Hermenéutica, democracia y emancipación. Filosofía, política, religión. Más allá del pensamiento débil (pp. 47-64). Nóbel.

Vattimo, G. (2000). La società trasparente. Garzanti.

Vattimo, G. (2006). Introducción a Heidegger. Gedisa.

Vattimo, G. (2007). Fundamentalismo democratico e dialettica del pensiero. En Academia de la Latinidad, Democracia profunda, reinvenciones nacionales y subjetividades emergentes (pp. 403-410). Editora Universitaria Candido Mendes.

Vattimo, G. (2009a). Addio a la verità. Meltemi.

Vattimo, G. (2009b). Ecce Comu. Paidós.

Vattimo, G. (2009c). Metafísica y violencia. Zabala, S. (comp.). Debilitando la filosofía. Ensayos en honor de Gianni Vattimo (pp. 451-475). Anthropos.

Vattimo, G. (2010). Del diálogo al conflicto. En T. Oñate, D. Leiro, A. Núñez y O. Cubo (eds.). El compromiso del espíritu actual. Con Gianni Vattimo en Turín (pp. 23-34). Aldebarán.

Vattimo, G. (2012). Della realtà. Fini della filosofia. Garzanti.

Vattimo, G. (2014). Esperando a los bárbaros. Fedun.

Vattimo, G. (2018). Essere e dintorni. La nave di Teseo.

Vattimo, G. y Rovatti, A. (1988). El pensamiento débil. Cátedra.

Vattimo, G. y Zabala, S. (2011). Hermeneutic communism. Columbia University Press.

Vattimo, G. y Zabala, S. (2017). Response to Perkins and Gillespie. En S. Mazzini, S. y O. Glyn-Williams O. (eds.), Making Communism Hermeneutical. Reading Vattimo and Zabala (pp.151-152). Springer.

White, S. K. (2009). Violence, Weak Ontology, and Late-Modernity. Political Theory, 37(6), 808-816. https://doi.org/10.1177/0090591709345464

Woessner, M. (2017). Hermeneutic Communism: Left Heideggerianism's Last Hope? En S. Mazzini y O. Glyn-Williams (eds.), Making Communism Hermeneutical. Reading Vattimo and Zabala. Springer, 35-48.

Woodward, A. (2009). The Verwindung of Capital: On the Philosophy and Politics of Gianni Vattimo. Symposium: Canadian Journal of Continental Philosophy, 13(1), 7399. https://doi.org/10.5840/symposium20091315Woodward.

Zabala, S. (2004). Gianni Vattimo: Nihilismo y emancipación. Paidós.

Zarria, S. y Maschke, G. (2016). El concepto de lo político de Carl Schmitt.

Versión de 1927. Res Publica. Revista de Historia de las Ideas Políticas, 22(1), 259-289. https://doi.org/10.5209/RPUB.63896 